powerful influence on neurones - recorded in other layers - that receive input from the 'suppressed' layer. Yet microiontophoretically applied bicuculline would not spread far enough to be effective in layers remote from the recording site. Thus Sillito and colleagues' estimate of the proportion of neurones influenced (directly or indirectly) by GABA-rnediated inhibition might well prove too low.

In any case, it is evident that both the redistribution of afferents within layer IV and a degree of interocular suppression (perhaps outside layer IV) contribute to the cortical effects of monocular deprivation. While the available evidence suggests that interocular suppression plays a secondary role, resolution of the issue must await detailed study of the laminar location and intracortical connectivity of 'suppressed' neurones, as well as attention to potential inhibitory neurotransmitters other than GABA. Plainly, Wiesel and Hubel's straightforward observations of eighteen years ago opened the door on complex features of cortical organization.

\title{
Global warming?
}

\section{from T.M.L. Wigley, P.D. Jones and P.M. Kelly}

IN 1975, Lamb and his colleagues ${ }^{1}$ noted that the downward trend of Northern Hemisphere surface temperatures, which had begun in the early 1940s, had come to an end - at least in the northern North Atlantic. Since then, the direction of the global temperature change has been a controversial issue. Some argue, justifiably, that we cannot be sure of global-mean conditions because there are such large gaps in the data coverage, particularly over the ocean and in the Southern Hemisphere. However, it can be argued that, because temperatures are more uniform over the oceans than the continents, large oceanic data gaps can be tolerated (see Barnett ${ }^{2}$ for an opposing view). Further controversy lies in whether or not surface temperatures are meaningful at all. Perhaps a better measure of largescale fluctuations in atmospheric temperature is the column-mean temperature, as determined, for instance, by the 1,000 to 500 mbar height difference. Doubts have been expressed by Parker ${ }^{3}$ as to the reliability of these data but, provided the limitations are taken into account, considerable insight into global temperature changes can be gained.

Much useful information can be gained from recent Russian publications. Borzenkova and his colleagues ${ }^{4}$ gave a series of annual mean temperature values averaged over the latitude belt 17.5-87.5 ${ }^{\circ} \mathrm{N}$ for the period 1881-1975 which show a marked warming since 1964. Despite criticisms $^{5}$, Vinnikov 6 has now convincingly shown that the data are homogeneous and do not suffer from discontinuities apparent in earlier work. Vinnikov also pointed out that the warming trend they had detected was certainly not spatially 'universal' ...

T.M.L. Wigley, P.D. Jones and P.M. Kelly are in the Climatic Research Unit, School of Environmental Sciences, University of East Anglia. "variations of air temperature at the surface of the Earth may have different signs over extensive areas of the globe in spccific seasons of the year, even against the background of a significant rise in average global characteristics"' (p. 97). Thus, while an overall warming may have occurred, quite large regions may still exhibit a cooling trend. Although the trend revealed by Borzenkova appears, therefore, to be well established, one comment ${ }^{5}$ must be accepted - that we do not know whether the warming is liable to continue into the future. All of this, of course, begs the questions of what is meant by 'trend', and how one determines the beginning of a trend, given the large year-to-year variability.

What has happened since 1975? A recent Russian paper $^{7}$ gives results up to and including 1978, and we $^{8}$ have independently made estimates of Northern Hemisphere average surface temperatures up to February 1981. Our own results, based on very much the same data as used by the Russians, naturally correlate highly with theirs. The data show 1972, 1974 and 1976 to be quite cold years, agreeing with the estimates of Barnett ${ }^{2}$ and Angell and Korshover ${ }^{9}$. In fact, the data show 1972 to have been the coldest year since 1917 . Vinnikov et al.'s data agree for 1972 and 1976, but they show 1974 as a warm year. A cooler 1974 and a cool year in 1976 reduce the magnitude of Borzenkova et al.'s 1964-1975 warming trend. However, 1977 was a warm year (the warmest since 1953) and both 1979 and 1980 were also relatively warm. The warming trend appears, therefore, to be continuing; but conditions are still considerably cooler than the balmy period between the late 1930s and the early 1950s.

Perhaps the most outstanding feature of recent years has been the 1981 Northern Hemisphere winter (December $1980-$ February 1981). This was the warmest winter on record (records began in
1881), equalling the value for 1944 . The next three warmest winters are, in order, 1926,1958 and 1980 . In the past two years we have, therefore, experienced two remarkably warm winters, contrasting sharply with the winters of 1969 and 1972 which were the two coldest winters since 1917. For the 1981 winter, especially in January and February, the maps published by the Free University of Berlin (Berliner Wetterkarte) show remarkable warm anomalies over northern Canada and Alaska, and over north-central Siberia with a much smaller-magnitude cool anomaly over the North Atlantic. Many places in northern Canada and Alaska recorded record warmth in January, some places being more than $16^{\circ} \mathrm{C}$ above the 1931-60 'normal'.

The warmth of the past two winters may be reflected in Northern Hemisphere snow cover. In a recent paper in Nature, Matson and Weisnet ${ }^{10}$ described changes in snow cover, based on satellite measurements, over the period 1967-1980. Over North America, a rising trend up to $16.9 \times 10^{6}$ $\mathrm{km}^{-2}$ in 1979 was followed by a sharp drop in $1980\left(15.1 \times 10^{6} \mathrm{~km}^{-2}\right)$. The 1981 value is even lower, $13.9 \times 10^{6} \mathrm{~km}^{-2}$, the lowest on record. For Eurasia the 1980 and 1981 values are both low (but not as low as the 1970 value), while for the whole hemisphere the values for 1980 and 1981 are $38.9 \times 10^{6} \mathrm{~km}^{-2}$ and $38.0 \times 10^{6} \mathrm{~km}^{-2}$, values surpassed only by the 1970 value $\left(37.2 \times 10^{6} \mathrm{~km}^{-2}\right)$ (1981 data from Michael Matson, NOAA/NESS, Washington, DC 20233). In spite of the correspondence between recent winter warmth and low snow cover, the overall correlation between these two variables is low. For the first 13 years of record the correlation coefficient between hemispheric winter snow cover and temperature was -0.03 . When 1980 and 1981 are included this rises to -0.40 !

It is difficult to know the significance of these recent events, but it is certainly premature to associate them with the effects of increasing atmospheric carbon dioxide. At present, the high inter-annual variability of surface temperatures (that is, the 'noise' of natural climatic variability) makes it impossible to identify the apparent trend with any particular causal mechanism. We note also that a similar warming trend has occurred before, between the late 1910s and around 1940. However, a few more consecutive warm winters, with continuing warmth in the other seasons, will doubtless give climatologists pause for thought.

\footnotetext{
L.amb, Malmberg \& Colebrook Nature 256, 479 (1975).

Barnetl Mon. Weath. Rev. 106, 1353 (1978)

2. Barnetl Mon. Weath. Rev. 106, 1353

3. Parker Met. Mag. 109, 129 (1980).

Borzenkova, Vinnikov, Spirina \& Stekhnovskii Meteor ologiya i Gidrologiya 1976(7), 27 (1976).

5. Rubinstiein Meteorologiya i Gidrologiya 1977(9), 106 (1977).

6. Vinnikov Meleorologiya i Gidrologiya 1977(9), $110(1977)$.

7. Vinnikov et al Meteorologiva i Gidrologiva 1989(6), 5 (1980).

8. Jones \& Wigley Climate Monitor 9, 43, 86, 109, 147 (1980).

9. Angell \& Korshover Mon. Weath. Rev. 105, 375 (1977).

10. Matson \& Weisne Nature 289, 451 (1981).
} 


\title{
Why mammalian gametes don't mix
}

\author{
from J. Michael Bedford
}

THROUGHOUT the Metazoa the reproductive isolation of a species is consistently reflected in the restricted affinities of sperm and egg. The possibilities for interspecific fertilization and the precise mechanisms that restrict this among mammals, including man, have been less than clear, but an understanding of the basis of this restriction is gradually emerging. An ability to dissect or overcome the specific barriers to cross fertilization could help us come nearer to a precise analysis of the mechanisms of the normal event. More practically, it may also soon offer an avenue for clinical evaluation of the fertilizing ability and even the chromosomes of human sperm. Considering the sequential steps of the conception process allows us to summarize what we know of the factors that prevent easy union of sperm and eggs from different mammals, and why further study of this should be rewarding.

The exact way that a specificity of sperm and eggs is achieved may vary. Sperm of teleost fish, for instance, must negotiate the specialized environment created around a small hole in the egg shell. Usually, however, organisms practicing external fertilization seem to depend primarily on elements in the egg coat and sperm surface whose 'fit' dictates a specificity of penetration; one that for sympatric marine species prevents the sea becoming a gamete mixing pot. Since the behavioural preliminaries to ejaculation and insemination could preserve a specificity of fertilization m mamınals, an extreme individuality of the character of their gametes might seem unnecessary. Nonetheless, despite changes in the character of both gametes in evolutionary transition from external fertilization to the rather complex interaction that characterizes fertilization in placental mammals, such an individuality persists. Cross-species fertilization can occasionally follow artificial insemination, or the mating that sometimes occurs in confined situations between related mammals. Further development then depends on the harmony of gene expression in the embryo and on its intrauterine relationship with the mother - one favoured possibly by the superficial rather than the intimate type of placenta. Such embryos often die during pregnancy (ferret x mink; goat $x$ sheep; rabbit $x$ hare), but others survive to adulthood as healthy individuals that may be wholly sterile (horse $\mathrm{x} z$ zebra) or not (ox x bison). In general, however, mammalian gametes tend to express their specific character at several points in the process of conception. As a consequence, fertilization will not occur readily even between members of the same Family such as the rat and mouse, let alone among mammals that differ more widely.
Preliminaries in the female. Incompatability could first be expressed in the foreign tract by failure of sperm to be transported to the site of fertilization in the Fallopian tube, to survive as viable cells, or to be capacitated (mammalian sperm are not able to fertilize immediately after ejaculation and must undergo a final maturation, capacitation, in the female tract). Little is known of sperm function in the native tract, and so the factors affecting foreign spermatozoa are hardly definable. There is no clear pattern to their longevity: occasionally it can be prolonged beyond that seen in the homologous tract (rabbit spermatozoa in the estrous rat

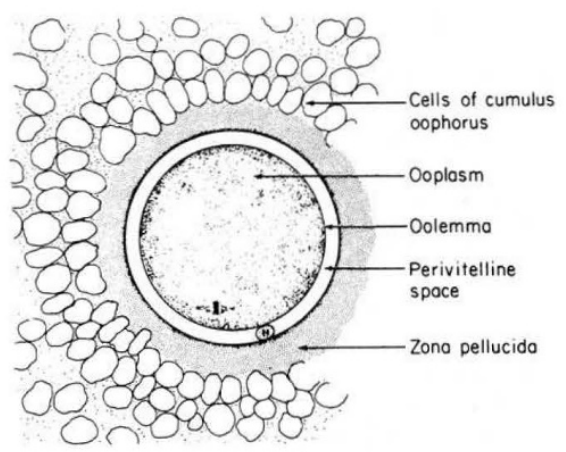

Fig.1 Diagram of a typical mammalian egg soon after ovulation that illustrates the various vestments through which the sperm must pass before being incorporated into the ooplasm.

uterus), but foreign spermatozoa more often die before they would in a native situation and before native spermatozoa in the same uterus or oviduct. Nor does the persistence of motility guarantee transport to the site of fertilization. As shown by the behaviour of human spermatozoa inseminated into the rabbit, maintenance of their motility in the vagina is no ready passport through the cervix to the uterine cavity. The Fallopian tube likewise tends to select the native male gamete from a mixed population of motile cells placed in the uterus, and one can only suspect involvement of the specific surface character of the sperm cell at either point of selection in the tract. On the other hand, capacitation does not appear to be an obstacle when motility is preserved and spermatozoa can experience the tubal environment. Moreover, the time required for capacitation seems more a function of the specific identity of the sperm than of the environment.

Sperm penetration of egg vestments. For gamete union to occur, sperm must first pass through the substantial barriers around the

J. Michael Bedford is Uris Foundation Professor of Reproductive Biology, Cornell University Medical College. newly ovulated egg (see Fig.1). The specificity of the immediate preliminaries to the union of mammalian gametes is difficult to elucidate. At the site of fertilization, little is known of the nature of the elements that promote the acrosome reaction, the role and specificity of action of acrosomal enzymes, and the exact function of the specific binding between the reacted sperm head and zona surface. Whether once capacitated, spermatozoa are then triggered to react by a specific signal or do so spontaneously is not resolved. The response of capacitated spermatozoa around foreign and native eggs in the same milieu might illustrate whether the egg coat provides a specific reaction (as it does in sea urchin) and if not, whether the cumulus/corona cell complex expresses a selective resistance towards reacted foreign sperm. That the zona pellucida does so is impressively illustrated by the many successes in interspecific fusion that follow its removal. How it exerts this barrier role still eludes us, again because the precise mechanism of homospecific penetration of the zona is largely unexplained. There is an element of 'Catch-22' in that uncapacitated spermatozoa (which cannot undergo the acrosome reaction) will of ten attach to the zona pellucida non-specifically in associations incompatible with penetration; but in attaining the capacitated state (in which they undergo the acrosome reaction), sperm probably undergo a surface change which imposes specificity in attachment/binding between the zona substance and sperm plasmalemma. At all events it is probable that specific entities, possibly glycoproteins, are exposed on the surface of the capacitated sperm cell membrane overlying the acrosome, intact or reacted - and that these bind effectively to complementary elements at the surface of the zona pellucida. In the mouse, one of three major glycoproteins that form the zona pellucida is implicated as the receptor through which specific or functional ligands are established. Is the tenacity of this binding the essential key? The answer must await resolution of the means by which spermatozoa normally penetrate the zona substance. The thrashing bound spermatozoon may need the stable union of the reacted peri-acrosomal plasmalemma with the zona surface as a base from which to intrude into the substance of the zona. It does not seem good sense, however, that the nowexposed inner membrane of the acrosome should bond with receptors throughout the zona, since that surface must oscillate and slide freely in cleaving a penetration slit. Neither of the prime factors being considered - a motive force imparted by the 